\title{
Antiplexin D1 Antibodies Relate to Small Fiber Neuropathy and Induce Neuropathic Pain in Animals
}

\author{
Takayuki Fujii, MD, PhD, Eun-Jae Lee, MD, PhD, Yukino Miyachi, MSc, Ryo Yamasaki, MD, PhD, \\ Young-Min Lim, MD, PhD, Kyoko linuma, MSc, Ayako Sakoda, MD, PhD, Kwang-Kuk Kim, MD, PhD, and \\ Jun-ichi Kira, MD, PhD
}

Neurol Neuroimmunol Neuroinflamm 2021;8:e1028. doi:10.1212/NXI.0000000000001028

\section{Abstract}

\section{Objectives}

To assess the prevalence of antiplexin D1 antibodies (plexin D1-immunoglobulin G [IgG]) in small fiber neuropathy (SFN) and the effects of these antibodies in vivo.

\section{Methods}

We developed an ELISA for plexin D1-IgG using a recombinant extracellular domain of human plexin D1 containing the major epitope and sera from 58 subjects previously studied with a standard tissue-based indirect immunofluorescence assay (TBA). We screened 63 patients with probable SFN and 55 healthy controls (HCs) for serum plexin D1-IgG using ELISA. The results were confirmed by TBA. IgG from 3 plexin D1-IgG-positive patients, 2 plexin D1-IgGnegative inflammatory disease controls, and 2 HCs was intrathecally injected into mice, which were assessed for mechanical and thermal hypersensitivity 24 and 48 hours after injection.

\section{Results}

The ELISA had $75 \%$ sensitivity and $100 \%$ specificity using the TBA as a standard, and the coincidence rate of ELISA to TBA was $96.6 \%$ (56/58). The frequency of plexin D1-IgG was higher in patients with SFN than in HCs $(12.7 \%$ [8/63] vs $0.0 \%$ [0/55], $p=0.007)$. Purified IgG from all 3 plexin D1-IgG-positive patients, but not 2 plexin D1-IgG-negative patients, induced significant mechanical and/or thermal hypersensitivity compared with IgG from HCs. In mice injected with plexin D1-IgG-positive but not D1-IgG-negative patient IgG, phosphorylated extracellular signal-regulated protein kinase immunoreactivity, an activation marker, was confined to small dorsal root ganglion neurons and was significantly more abundant than in mice injected with HC IgG.

\section{Conclusions}

Plexin D1-IgG is pathogenic but with low prevalence and is a potential biomarker for immunotherapy in SFN.

\author{
Correspondence \\ Dr. Kira \\ kira@neuro.med.kyushu-u.ac.jp
}




\section{Glossary}

ALS = amyotrophic lateral sclerosis; ANOVA = analysis of variance; $\mathbf{C V}=$ coefficient of variation; $\mathbf{D M}=$ diabetes mellitus; DRG = dorsal root ganglia; FGFR3 = fibroblast growth factor receptor 3; HC = healthy control; IDC = inflammatory disease control; IgG = immunoglobulin G; iSFN = idiopathic SFN; NeP = neuropathic pain; OD = optical density; PBS = phosphatebuffered saline; $\mathbf{p E R K}=$ phosphorylated extracellular signal-regulated protein kinase; rhPlexin D1 = recombinant human plexin D1 extracellular domain; RT = room temperature; SFN = small fiber neuropathy; SFN-SIQ = SFN Symptom Inventory Questionnaire; sSFN = secondary SFN; TBA = tissue-based indirect immunofluorescence assay; TS-HDS = trisulfated heparin disaccharide.

Small fiber neuropathy (SFN) involving unmyelinated $\mathrm{C}$-fibers and thinly myelinated $\mathrm{A} \delta$-fibers presents neuropathic pain $(\mathrm{NeP}) /$ allodynia, paresthesia, and loss of pinprick and thermal sensation, together with a variety of autonomic symptoms. ${ }^{1-3}$ Although SFN is associated with many pathologic conditions, ${ }^{4,5}$ no identifiable cause can be found in approximately half of patients with SFN, and these cases are termed idiopathic SFN (iSFN). ${ }^{4,5}$ Recently, autoantibodies against fibroblast growth factor receptor 3 (FGFR3) and trisulfated heparin disaccharide (TS-HDS) were reported in a fraction of patients with iSFN. ${ }^{6,7}$ However, the causative roles of these autoantibodies remain uncertain because reproducibility in animal experiments has not been demonstrated.

We reported antiplexin D1 antibody (plexin D1immunoglobulin $G[\operatorname{IgG}]$ ) in a fraction of patients with $\mathrm{NeP}$ with underlying neuroinflammatory diseases. ${ }^{8}$ Plexin D1-IgG specifically binds to unmyelinated small painconducing neurons in dorsal root ganglia (DRG), ${ }^{8}$ where the blood-nerve barrier is absent and autoantibodies have free access. ${ }^{9}$ Plexin D1-IgG was also detected in patients with idiopathic painful trigeminal neuropathy presenting facial pain and bound to trigeminal ganglion neurons. ${ }^{10}$ These observations prompted us to assess the prevalence of plexin D1-IgG in patients with SFN and to evaluate the painprovoking effects of intrathecally-injected plexin D1-IgG in mice.

\section{Methods}

\section{Participants}

To establish an indirect ELISA for plexin D1-IgG, we used sera from 8 patients with $\mathrm{NeP}$ with plexin D1-IgG diagnosed by a tissue-based indirect immunofluorescence assay (TBA) and from 50 non-NeP patients without plexin D1-IgG, including 30 disease controls consisting of 10 cases with autoimmune/inflammatory diseases and 20 healthy controls (HCs), as described in our previous study. ${ }^{8}$ In the SFN cohort study, 38 patients with iSFN and 25 secondary patients with SFN (sSFN) with potential causes of SFN (table 1) were consecutively enrolled between August 2018 and September 2019, 40 from Asan Medical Center in Korea, and 23 from Kyushu University Hospital in Japan. All patients with SFN fulfilled the criteria for probable or definite SFN according to the clinically based SFN definition, including the distribution of symptoms and signs suggestive of SFN (table 1). ${ }^{1,3}$ For controls, 55 HCs were enrolled, 30 from Asan Medical Center in Korea and 25 from Kyushu University Hospital in Japan. There were no significant differences in sex or age between patients with SFN and HCs (table 1).

\section{Clinical Evaluation}

To characterize the clinical features of patients with SFN with plexin D1-IgG, we retrospectively reviewed their demographic data, neurologic findings, comorbidities, and SFN Symptom Inventory Questionnaire (SFN-SIQ), which interrogates sensory symptoms, pain, and autonomic complaints. ${ }^{11}$

\section{Development of Indirect ELISA for Plexin D1-IgG}

TBA, the current gold standard for plexin D1-IgG identification, ${ }^{8,10}$ is unsuitable for large-scale screening studies because of low sensitivity, despite its high specificity. Therefore, we developed an indirect ELISA for plexin D1IgG. Briefly, 96-well plates (Corning, New York, NY) were coated overnight at $4^{\circ} \mathrm{C}$ with $0.1 \mu \mathrm{g} / \mathrm{mL}$ of the recombinant human plexin D1 extracellular domain (rhPlexin D1; amino acids 47-1,271) derived from NS0 cells (mouse myeloma cell line; R\&D Systems, Minneapolis, MN, USA) in phosphatebuffered saline (PBS). To quantify the serum-specific background noise, a noncoated well was prepared for each serum of interest by incubating PBS without the plexin D1 protein. ${ }^{7}$ The plates were washed with $0.1 \%$ PBS-Tween 20 , and all wells were then blocked with 5\% skimmed milk for 1 hour at room temperature (RT). After washing, the plates were incubated with diluted serum samples (1:200 in $2 \%$ skimmed milk) for 1 hour at RT. The plates were washed and incubated for 1 hour at RT with a horseradish peroxidase-conjugated goat antihuman IgG Fc antibody (Abcam, Cambridge, United Kingdom). After washing, 3,3',5,5' -tetramethyl benzidinesubstrate solution (Nacalai Tesque, Kyoto, Japan) was added and incubated for 10 minutes. After adding $1 \mathrm{M} \mathrm{H}_{2} \mathrm{SO}_{4}$ to each well to stop the reaction, the optical density (OD) at 450 $\mathrm{nm}$ was measured on a multimicroplate reader (CORONA, Tokyo, Japan). For interassay coefficients of variation (CVs), 3 samples from 1 patient with plexin D1-IgG and from 2 patients without plexin D1-IgG were analyzed in duplicate in 3 different runs. ${ }^{12}$ The difference between the OD of the plexin D1-coated well and that of the noncoated well (the 
Table 1 Demographic Features of Patients With SFN and HCS

\begin{tabular}{|c|c|c|c|}
\hline & Patients with SFN ${ }^{a}(n=63)$ & HCs $(n=55)$ & $p$ Value \\
\hline Male/female (ratio) & $31 / 32(1.0: 1.0)$ & 18/37 (1.0:2.1) & N.S. \\
\hline Age at examination, $y^{b}$ & $58.0(52.0-69.0)$ & $57.0(44.0-64.0)$ & N.S. \\
\hline Positive rate of ELISA (\%) & $8 / 63(12.7)$ & $2 / 55(3.6)$ & N.S. \\
\hline Positive rate of ELISA plus TBA (\%) & $8 / 63(12.7)$ & $0 / 55(0.0)$ & 0.007 \\
\hline Underlying diseases & $\begin{array}{l}38 \text { idiopathic, } 13 \text { with DM, } 5 \text { with SLE, } \\
3 \text { with a history } \\
\text { of cancer chemotherapy, } 2 \text { with RA, } 1 \text { each } \\
\text { with PR3-ANCA or SSC }\end{array}$ & & \\
\hline
\end{tabular}

Abbreviations: DM = diabetes mellitus; $\mathrm{HCS}=$ healthy controls; N.S. = not significant; PR3-ANCA = proteinase-3-antineutrophil cytoplasmic antibodies; RA = rheumatoid arthritis; SFN = small fiber neuropathy; SLE = systemic lupus erythematosus; SSC = systemic scleroderma; TBA = tissue-based indirect immunofluorescence assay.

The Mann-Whitney $U$ test was used to compare continuous variables, and the $\chi^{2}$ test or Fisher exact probability test (when criteria for the $\chi^{2}$ test were not fulfilled) was used to compare the categorical variables between patients with SFN and HCs.

a All patients with SFN fulfilled the criteria for probable SFN according to the clinically based SFN definition, including the distribution of symptoms and signs suggestive of SFN. ${ }^{1,3}$ The diagnosis can be graded as follows: probable; presence of length-dependent symptoms, clinical signs of small-fiber damage, and normal sural nerve conduction study (NCS), and definite; presence of length-dependent symptoms, clinical signs of small-fiber damage, normal sural NCS, and reduced intraepidermal nerve fiber density at the ankle, and/or abnormal thermal thresholds.

${ }^{b}$ Median (interquartile range).

corrected OD value) was calculated, and the test was considered "ELISA-positive" when the corrected OD value was above the mean plus 5 SDs of the 50 plexin D1-IgG-negative controls (30 diseases controls and $20 \mathrm{HCs}){ }^{7}$

\section{TBA}

Sera from all 58 participants used in the ELISA development were tested by TBA using mouse DRG, as described in our previous study. ${ }^{10}$ IgG subtypes were determined using secondary fluorescein isothiocyanate-conjugated mouse antihuman antibodies specific for IgG1, IgG2, IgG3, or IgG4 (Sigma-Aldrich, St. Louis, MO). To confirm the antibody specificity to plexin D1, immunoadsorption tests were performed with rhPlexin D1 by TBA. ${ }^{10}$ In the SFN cohort study, we applied TBA as a confirmatory test for ELISA plexin D1IgG positivity. ${ }^{8,10}$

\section{IgG Purification}

Purification of IgG from human sera was performed using Protein G HP SpinTrap columns (GE Healthcare, Little Chalfont, United Kingdom) according to the manufacturer's protocol.

\section{Passive Transfer of Patient-Derived Plexin D1-IgG to Mice}

Anesthetized female ICR mice (10-12 weeks old) were intrathecally injected with $20 \mu \mathrm{L}$ purified IgG from 3 plexin D1IgG-positive patients with $\mathrm{NeP}$ (patients 1,2, and 3) with and without preabsorption with rhPlexin D1 $(2.0 \mu \mathrm{g} / \mathrm{mL}), 2$ plexin D1-IgG-negative inflammatory disease controls (IDCs) without SFN, and $2 \mathrm{HCs}$ (detailed information of subjects is in table e-1, links.lww.com/NXI/A497) by percutaneous puncture into the intervertebral space between the fifth and sixth lumbar vertebrae. ${ }^{13,14}$ Injection accuracy was ensured by an injection-induced tail flick. ${ }^{15}$ We assessed mechanical and thermal pain hypersensitivity using von Frey and hot plate tests 24 hours after injection because the most potent effects of antismall DRG neuron autoantibodies derived from patients on stimulus-evoked pain-like behavior in passive transfer models were observed 24 and 48 hours after intrathecal injection in a previous study. ${ }^{14}$ Mechanical pain hypersensitivity was assessed using calibrated von Frey filaments (0.04-0.6 g; Danmic Global, San Jose, CA), as we have described previously. ${ }^{16}$ Each filament was presented 10 times, and the number of positive responses multiplied by 10 was recorded as the percent response. To examine thermal pain hypersensitivity, mice were placed on a digital hot plate (AS ONE, Osaka, Japan) set to $48^{\circ} \mathrm{C}$. The latency to jump, lift, and/or lick a hind paw was measured, at which point mice were removed. ${ }^{17}$ Mice were video recorded during the hot plate test. To avoid tissue damage, a cutoff of 60 seconds was defined. This temperature was chosen because it is at the low end of the noxious range usually used to perform this test. ${ }^{18}$ Behaviors were assessed and compared by 2 independent observers. The 2 sensory tests were separately conducted 1 hour apart.

In addition, we evaluated phosphorylated extracellular signalregulated protein kinase ( $p E R K$ ) immunoreactivity in DRG neurons from passive transfer mice as a marker indicating activation of primary afferent DRG neurons. ${ }^{19}$ L5 DRG from passive transfer mice were removed, fixed in $10 \%$ buffered formalin, paraffin-embedded, and sectioned at $4 \mu \mathrm{m}$. The sections were then incubated overnight with a mouse antipERK antibody (Santa Cruz Biotechnology, Santa Cruz, CA; dilution $1: 100$ ) at $4^{\circ} \mathrm{C}$. After rinsing, the sections were treated with a streptavidin-biotin complex. Immunoreactivity was detected using 3,3'-diaminobenzidine, and sections were counterstained with hematoxylin. For quantification of DRG neurons, 2 L5 DRG sections were randomly selected for each 
mouse. The numbers of total and pERK-labeled DRG neurons per section were counted to determine changes in pERK expression. ${ }^{19}$ The average percentage of labeled neurons among total neurons was obtained for each mouse.

\section{Standard Protocol Approvals, Registrations, and Patient Consents}

The research protocol for the retrospective study and the data privacy procedures for human samples were approved by the Kyushu University Ethics Committee (\#29-40, \#30-164, \#2019-328) and the institutional review board of Asan Medical Center (20190628). All patients and controls provided written informed consent. Animal experiments were performed according to the protocols approved by the Institutional Animal Care and Use Committee at Kyushu University (\#A29-257, \#A20-123).

\section{Statistical Analysis}

Statistical comparisons for the behavioral tests of passive transfer mice and the average percentage of pERK-labeled neurons among total DRG neurons were performed by 1-way analysis of variance (ANOVA) with the Dunnett test for multiple comparisons between the HCs' IgG-treated group and the patients' IgG-treated groups. ${ }^{20}$ The data are expressed as the mean \pm SEM. Statistical significance was set at $p<0.05$.

\section{Data Availability}

Any data not published within the article will be shared in anonymized form by request from any qualified investigator.

\section{Results}

\section{Indirect ELISA for Plexin D1-IgG}

The inter-assay CV of each tested serum $(7.5 \%, 10.6 \%$, and $13.8 \%)$ was less than the minimally acceptable CV of $15 \%{ }^{12}$ Using a cutoff OD value of the mean +5 SDs of 30 disease controls and $20 \mathrm{HCs}$ (0.163), 6 patients (75\%) with plexin D1-IgG by TBA were positive for plexin D1-IgG by ELISA, whereas all 50 disease controls, including 10 cases with autoimmune/inflammatory diseases and HCs without plexin D1-IgG by TBA, were all negative for plexin D1-IgG by ELISA (figure 1A). Hence, the sensitivity of the ELISA was $75 \%(6 / 8)$ among plexin D1-IgG-seropositive individuals, and the specificity was $100 \%(50 / 50)$ among plexin D1-IgG seronegative individuals, using TBA as the standard evaluation method. In summary, the overall coincidence rate of the ELISA to TBA was $96.6 \%$ (56/58) (figure 1B).

\section{The Prevalence of Plexin D1-IgG in Patients With SFN}

In the SFN cohort study, plexin D1-IgG was positive in 8 of 63 (12.7\%) of all patients with SFN by ELISA, including 6 of 38 (15.8\%) patients with iSFN, 2 of 25 (8.0\%) patients with sSFN, both of whom had diabetes mellitus (DM), and 2 of 55 (3.6\%) HCs (figure 1C). By TBA, IgG from all 8 ELISApositive patients with SFN bound to IB4-positive small DRG neurons, and they were deemed to be positive for plexin D1-
IgG (figure e-1A, links.lww.com/NXI/A495 and table 1). Conversely, no ELISA-positive HCs bound to DRG neurons (figure 1D and table 1). All 8 plexin D1-IgG-positive patients were probable SFN without skin biopsy. Correlation analysis showed a significant positive correlation between the corrected OD value and disease duration in patients with SFN with plexin D1-IgG (Spearman rank correlation; $r_{\mathrm{s}}=0.9639, p$ $=0.0001$, figure $1 \mathrm{E})$. By contrast, there was no correlation between the corrected OD value and the age at sampling $\left(r_{\mathrm{s}}=\right.$ $0.2381, p=0.5702)$ or onset $\left(r_{s}=-0.2143, p=0.6103\right)$. In a subclass analysis of plexin D1-IgG, 5 had only IgG2, 2 had predominant IgG2 and weak IgG1, and 1 had only IgG1, which indicates IgG2 predominance (87.5\%) (figure e-1B).

\section{Comparison of Clinical Features Between Patients With SFN With and Without Plexin D1-IgG}

The clinical findings of 8 patients with SFN with plexin D1IgG are described in tables 2 and 3. Patients with SFN with plexin D1-IgG showed late-middle age onset (mean $\pm \mathrm{SD}=$ $56.6 \pm 12.8$ years), chronic disease course (100\%), and burning feet (85.7\%) in SFN-SIQ. Next, we compared clinical features between the 8 patients with SFN with plexin D1-IgG and 55 patients with SFN without plexin D1-IgG (table 3). Disease duration at the time of serum sampling was significantly longer in patients with SFN with plexin D1-IgG than in those without (mean $\pm \mathrm{SD} ; 9.3 \pm 8.2$ vs $4.5 \pm 4.4, p=0.0414$ ). Concerning the quality of $\mathrm{NeP}$, patients with SFN with plexin D1-IgG showed a higher frequency of pricking pain than those without $(62.5 \%$ vs $21.8 \%, p=0.0278)$. There were no differences in any other parameters examined between the 2 groups.

\section{Induction of NeP in Mice by Plexin D1-IgG From Patients}

As for sensitivity to punctate mechanical stimuli using von Frey filaments, mice treated with purified IgG from patients 1,2 , and 3 showed significantly higher reaction rates to each stimulation strength $(0.07,0.16,0.40$, and $0.60 \mathrm{~g}$ filaments $)$ compared with control IgG-treated mice 24 hours after injection (1-way ANOVA with Dunnett test; $p<0.01$ ) (figure $2 A)$. Conversely, there were no significant differences in the reaction rates to each stimulation strength between mice treated with IgG from $\mathrm{HCs}$ and mice treated with IgG from 2 IDCs or patients 1,2 , and 3 preabsorbed with rhPlexin D1 (figure 2A). The hot plate test showed that the withdrawal latency in mice treated with IgG from patient 1 was significantly shorter than that in mice treated with control IgG (mean \pm SEM; $17.2 \pm 2.7$ and $32.5 \pm 2.4$ seconds, respectively: 1-way ANOVA with Dunnett test; $p<0.05$ ), whereas the difference disappeared with rhPlexin D1 preincubation (figure e-2A, links.lww.com/NXI/A496). However, no significant differences in withdrawal latencies were found between mice treated with control IgG and IgG from 2 IDCs or patients 2 and 3, irrespective of the presence or absence of preabsorption (figure e-2A). For all IgGs examined, however, neither mechanical nor thermal pain 
A

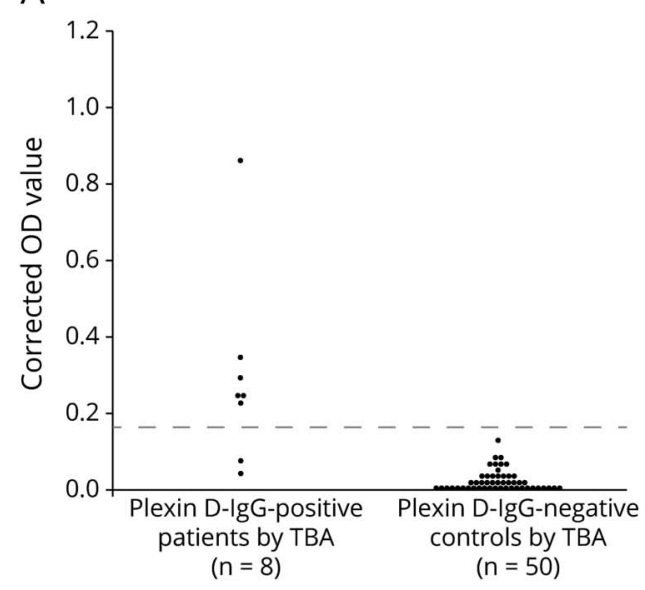

C

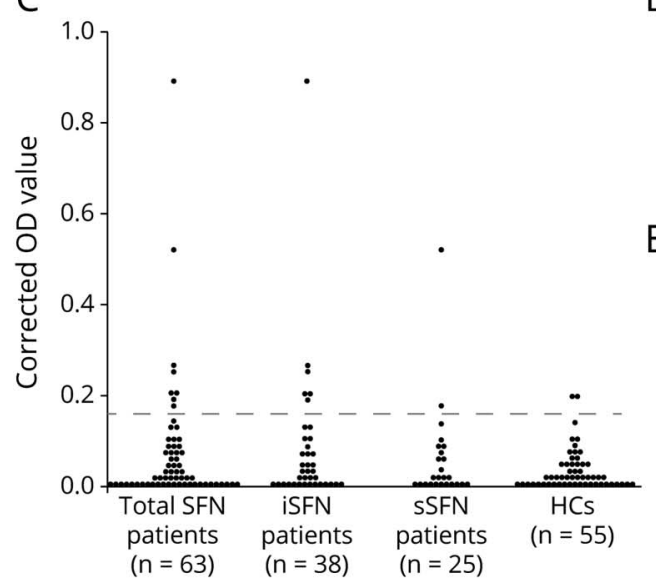

B. Comparison between the newly established ELISA and TBA for Plexin D1-IgG

\begin{tabular}{ccccc} 
& & \multicolumn{3}{c}{ TBA results } \\
\cline { 3 - 5 } & & Positive & Negative & Total \\
\hline ELISA results & Positive & 6 & 0 & 6 \\
& Negative & 2 & 50 & 52 \\
Total & 8 & 50 & 58 \\
\hline Data analysis Sensitivity & $75 \%(6 / 8)$ & & \\
Specificity & & $100 \%(50 / 50)$ \\
Coincidence \\
rate
\end{tabular}

D
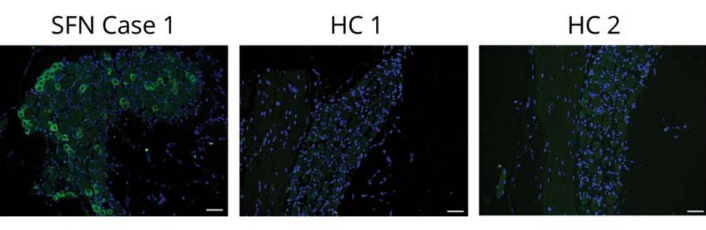

E

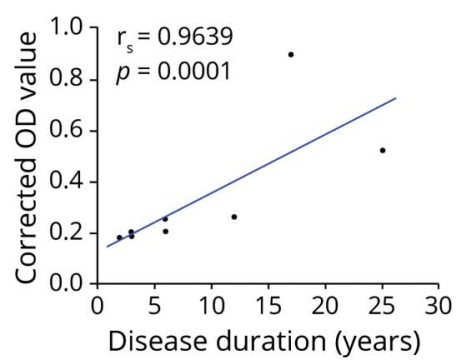

(A) Indirect ELISA for plexin D1-IgG in a previous cohort of 8 patients with NeP with plexin D1-IgG and 50 non-NeP patients (30 disease controls and 20 HCs) previously determined by TBA. Disease controls included 6 with amyotrophic lateral sclerosis; 4 each with multiple system atrophy, systemic lupus erythematosus, and neuro-Behçet disease; 3 with hereditary spinocerebellar degeneration; 2 each with Parkinson disease, normal pressure hydrocephalus, and Sjögren syndrome; and 1 each with Alzheimer disease, dementia with Lewy bodies, and corticobasal degeneration. The difference in OD values between plexin D1-coated wells and D1-uncoated wells (corrected OD value) was calculated, and the test was considered "ELISA-positive" when the corrected OD value was above the mean + 5 SD of the 50 plexin D1-IgG-negative controls determined by TBA (0.163, dotted line). Six of 8 patients with NeP with plexin D1-IgG by TBA were positive for plexin D1-IgG by ELISA, whereas all 50 disease controls and HCs without plexin D1-IgG by TBA were negative for plexin D1-IgG by ELISA. (B) Comparison of the newly established ELISA with TBA for plexin D1-IgG. The overall coincidence rate of ELISA to TBA was 96.6\% (56/58). (C) Indirect ELISA for plexin D1-IgG in the present SFN cohort. The difference in OD values between plexin D1-coated wells and D1-uncoated wells (corrected OD value) was calculated, and the test was considered "ELISA-positive" when the corrected OD value was above 0.163 (dotted line). Plexin D1-IgG was positive in 8 of 63 $(12.7 \%)$ of all patients with SFN, including 6 of 38 (15.8\%) patients with iSFN, 2 of 25 (8.0\%) patients with sSFN, and 2 of 55 (3.6\%) HCs by ELISA. (D) IgG (green) from a representative patient with SFN (iSFN Case 1 in table 2) showed positive immunostaining of mouse small DRG neurons, whereas there was no significant immunoreactivity in 2 ELISA-seropositive HCs (HC 1 and HC 2). Nuclei are counterstained with 4',6-diamidino-2-phenylindole (DAPI) (blue). (E) Correlation between the corrected OD value and the disease duration in patients with SFN with plexin D1-IgG ( $\mathrm{n}=8$ ). There was a significant positive correlation between them (Spearman rank correlation; $r_{\mathrm{s}}=0.9639, p=0.0001$ ). Even after 1 outlier with the highest optical density was removed, the correlation between the corrected OD value and the disease duration remained significant $\left(r_{\mathrm{s}}=0.982, p<0.0001\right)$. $\mathrm{HC}=$ healthy control; IgG $=$ immunoglobulin G; iSFN = idiopathic small fiber neuropathy; OD = optical density; SFN = small fiber neuropathy; sSFN = secondary small fiber neuropathy; TBA = tissue-based indirect immunofluorescence assay.

hypersensitivity was noted in mice 48 hours after injection (figures e-2, B and C).

\section{Activation of Small DRG Neurons by Plexin D1-IgG}

The average percentages of pERK-labeled neurons among total DRG neurons in mice treated with purified IgG from patients 1,2 , and 3 were significantly greater than those of mice treated with control IgG 24 hours after injection (mean \pm SEM; $6.7 \% \pm 1.0 \%, 9.7 \% \pm 1.7 \%, 5.9 \% \pm 1.0 \%$, and $1.9 \% \pm$ $0.6 \%$, respectively: 1 -way ANOVA with Dunnett test; $p<$
0.01) (figures 2B and e-2, D and E, links.lww.com/NXI/ A496). Most of these pERK-labeled neurons were small DRG neurons ( $\leq 25 \mu \mathrm{m}$ in diameter) (figures $2, \mathrm{~B}$ and $\mathrm{C}$ and e2D). ${ }^{21}$ Preabsorption of these patients' IgG with rhPlexin D1 abolished the increased expression of pERK in DRG neurons; there was no significant difference in the average percentage of pERK-labeled neurons among total DRG neurons between control IgG and preabsorbed IgG from patients 1, 2, and 3 (figures $2 \mathrm{~B}$ and $\mathrm{e}-2, \mathrm{D}$ and $\mathrm{E}$ ). This increase in pERK expression was subsided 48 hours after injection (figure e-2, F and $G$ ). Because the amounts of human IgG used for a single 
Table 2 Clinical Features of Patients With SFN With Plexin D1-IgG

\begin{tabular}{|c|c|c|c|c|c|c|c|}
\hline Case & $\begin{array}{l}\text { Sex/age at } \\
\text { examination, y }\end{array}$ & $\begin{array}{l}\text { Age at } \\
\text { onset, } y\end{array}$ & $\begin{array}{l}\text { Disease } \\
\text { duration, y }\end{array}$ & Coexisting disorders & The distribution and quality of pain & $\begin{array}{l}\text { The presence } \\
\text { of SFN-SIQ }\end{array}$ & $\begin{array}{l}\text { IgG } \\
\text { subclass }\end{array}$ \\
\hline $\begin{array}{l}\text { iSFN } \\
\text { case } 1\end{array}$ & $F, 74$ & 71 & 3 & None & Bilateral feet and distal legs pain (burning) & N.A. & $\lg \mathrm{g} 2$ \\
\hline $\begin{array}{l}\text { iSFN } \\
\text { case } 2\end{array}$ & $\mathrm{M}, 58$ & 52 & 6 & Prostate cancer & Bilateral feet pain (burning and pricking) & $\begin{array}{l}\text { SIQ } 1,4,5,6,11, \\
\text { and } 12\end{array}$ & $\lg \mathrm{g} 2$ \\
\hline $\begin{array}{l}\text { iSFN } \\
\text { case } 3\end{array}$ & $F, 71$ & 65 & 6 & None & $\begin{array}{l}\text { Bilateral hands, distal arms, feet, and } \\
\text { distal legs pain (burning and pricking) }\end{array}$ & $\begin{array}{l}\text { SIQ } 1,3,4,5,6,7 \\
8,10,11 \text {, and } 13\end{array}$ & $\operatorname{lgG1}$ \\
\hline $\begin{array}{l}\text { iSFN } \\
\text { case } 4\end{array}$ & $\mathrm{M}, 51$ & 48 & 3 & None & $\begin{array}{l}\text { Left hand and distal arm pain (pricking } \\
\text { and aching) }\end{array}$ & SIQ 12 and 13 & $\begin{array}{l}\operatorname{lgG2}> \\
\operatorname{lgG} 1\end{array}$ \\
\hline $\begin{array}{l}\text { iSFN } \\
\text { case } 5\end{array}$ & $F, 81$ & 69 & 12 & $\begin{array}{l}\text { Atopic dermatitis, } \\
\text { hepatocellular carcinoma } \\
\text { without chemotherapy }\end{array}$ & $\begin{array}{l}\text { Bilateral tongue and feet pain (burning, } \\
\text { pricking, allodynia, and hyperalgesia) }\end{array}$ & $\begin{array}{l}\text { SIQ } 3,6,7,10, \\
\text { and } 11\end{array}$ & $\lg G 2$ \\
\hline $\begin{array}{l}\text { iSFN } \\
\text { case } 6\end{array}$ & $\mathrm{M}, 73$ & 56 & 17 & $\begin{array}{l}\text { Allergic rhinitis, acute } \\
\text { myocardial infarction }\end{array}$ & $\begin{array}{l}\text { Bilateral feet pain (burning, aching, and } \\
\text { hyperalgesia) }\end{array}$ & SIQ 11 & $\begin{array}{l}\lg G 2> \\
\lg G 1\end{array}$ \\
\hline $\begin{array}{l}\text { sSFN } \\
\text { case } 1\end{array}$ & $M, 62$ & 60 & 2 & DM & $\begin{array}{l}\text { Bilateral hands and feet pain (burning } \\
\text { and pricking) }\end{array}$ & $\begin{array}{l}\text { SIQ } 6,10,11,12, \\
\text { and } 13\end{array}$ & $\lg G 2$ \\
\hline $\begin{array}{l}\text { sSFN } \\
\text { case } 2\end{array}$ & $M, 57$ & 32 & 25 & DM & $\begin{array}{l}\text { Bilateral hands and feet pain (burning } \\
\text { and electric-like) }\end{array}$ & $\begin{array}{l}\text { SIQ } 1,3,4,6,7,8 \\
9,11, \text { and } 13\end{array}$ & $\lg G 2$ \\
\hline
\end{tabular}

Abbreviations: IgG = immunoglobulin G; iSFN = idiopathic small fiber neuropathy; N.A. = not available; SFN = small fiber neuropathy; SFN-SIQ = small fiber neuropathy-Symptoms Inventory Questionnaire; SSFN = secondary small fiber neuropathy.

SFN-SIQ symptoms: 1 = altered sweating pattern; 2 = diarrhea; $3=$ constipation; $4=$ micturition problems; $5=$ dry eyes; $6=$ dry mouth; $7=$ orthostatic dizziness; $8=$ palpitations; $9=$ hot flashes; 10 = sensitive skin legs; 11 = burning feet; $12=$ intolerance for sheets; $13=$ restless legs. The answer options of the SFN-SIQ include "never = 0," "sometimes = 1," "often = 2," and "always = 3." A symptom is considered to be present when the score is 1 or higher.

intrathecal injection were relatively small, we could not immunohistochemically detect any significant binding of human IgG to DRG neurons in the injected mice. However, by indirect IFA, we confirmed the specific binding of IgG from patients to small DRG neurons on tissue sections, which was abolished by preabsorption with rhPlexin D1 (figures $2 \mathrm{~B}$ and e-2D). Furthermore, there was no significant difference in the average percentage of pERK-labeled neurons among total DRG neurons between control IgG and IgG from 2 IDCs both 24 and 48 hours after injection (figure e-2, E and G).

\section{Discussion}

All patients with plexin D1-IgG-positive SFN had chronic persistent pricking or burning pain in a length-dependent distribution, suggesting that plexin D1-IgG is associated with typical SFN manifestations. ${ }^{1}$ Although 1 study reported a female preponderance of iSFN $(75 \%),{ }^{22}$ we did not find any sex preponderance in plexin D1-IgG-positive iSFN. A significant positive correlation of antiplexin D1-IgG levels with disease duration indicates affinity maturation of the antibody over the disease course. Significantly longer disease duration compared with plexin D1-IgG-negative SFN and absence of acute onset SFN suggests that a longer period is required for full-blown SFN in plexin D1-IgG. Alternatively, plexin D1IgG may emerge as a consequence of long-term small fiber neuron damage because 2 patients with sSFN with DM also carried plexin D1-IgG. Plexin D1-IgG was not detected in collagen-vascular disease patients without $\mathrm{NeP}$ in this or previous $^{8}$ studies or even in patients with sSFN with collagenvascular diseases in this study. We thus consider that plexin D1-IgG does not emerge in patients with autoimmune/ inflammatory disease unless they develop $\mathrm{NeP}$. As in the sSFN cohort, patients with Sjögren syndrome, who occasionally develop $\mathrm{SFN}^{23}$ were not enrolled in this study. Therefore, it is important to investigate plexin D1-IgG in this population in the future.

Plexin D1-IgG was originally discovered in patients with $\mathrm{NeP}$ with underlying neuroinflammatory diseases, such as atopic myelitis, multiple sclerosis, and neuromyelitis optica spectrum disorders. ${ }^{8}$ Although the pain manifestations are similar in $\mathrm{NeP}$ and SFN cohorts, the antibody-positive $\mathrm{NeP}$ cases showed a young age at onset and female preponderance, reflecting the features of background diseases. Given that childhood-onset SFN is not rare and is often caused by dysimmunity and improved by immunotherapy, ${ }^{2,24,25}$ plexin D1-IgG should be examined in childhood-onset SFN in future studies.

Although the precise mechanism of iSFN remains elusive, 2 autoantibodies were reported to be associated with iSFN: IgM anti-TS-HDS found in $37 \%(57 / 155)$ of iSFN vs $11 \%(8 / 71)$ of patients with amyotrophic lateral sclerosis (ALS) and antiFGFR3-IgG found in $15 \%(23 / 155)$ of patients with iSFN vs $3 \%(1 / 31)$ of patients with ALS. ${ }^{6}$ The former was originally described in 5 IgM paraproteinemia cases presenting with a painful, predominantly sensory polyneuropathy, ${ }^{26}$ whereas 
Table 3 Demographic and Clinical Features of Patients With SFN With and Without Plexin D1-IgG

\begin{tabular}{|c|c|c|c|}
\hline & $\begin{array}{l}\text { Plexin D1-IgG-positive patients } \\
\text { with SFN }(n=8)\end{array}$ & $\begin{array}{l}\text { Plexin D1-lgG-negative patients } \\
\text { with SFN }(n=55)\end{array}$ & $p$ Value \\
\hline Female, n (\%) & $3 / 8(37.5)$ & $29 / 55(52.7)$ & N.S. \\
\hline Age at time of serum sampling, $y$, mean \pm SD & $65.9 \pm 10.3$ & $56.9 \pm 12.3$ & N.S. \\
\hline Age at disease onset, $y$, mean \pm SD & $56.6 \pm 12.8$ & $52.4 \pm 12.4$ & N.S. \\
\hline $\begin{array}{l}\text { Disease duration at time of serum } \\
\text { sampling, } y, \text { mean } \pm S D\end{array}$ & $9.3 \pm 8.2$ & $4.5 \pm 4.4$ & 0.0414 \\
\hline Presence or history of atopic diseases, $\mathbf{n}(\%)$ & $2 / 8(25.0)$ & 10/55 (18.2) & N.S. \\
\hline Presence or history of malignancy, $n$ (\%) & $2 / 8(25.0)$ & $10 / 55(18.2)$ & N.S. \\
\hline \multicolumn{4}{|l|}{ Disease onset, $\mathbf{n}(\%)$} \\
\hline Acute & $0 / 8(0.0)$ & $2 / 55(3.6)$ & N.S. \\
\hline Subacute & $0 / 8(0.0)$ & $4 / 55(7.3)$ & N.S. \\
\hline Chronic & $8 / 8(100.0)$ & $49 / 55(89.1)$ & N.S. \\
\hline \multicolumn{4}{|l|}{ SFN-SIQ (score 1 or higher), n (\%) } \\
\hline Altered sweating pattern & $4 / 7(57.1)$ & $14 / 43(32.6)$ & N.S. \\
\hline Diarrhea & $0 / 7(0.0)$ & $8 / 43(18.6)$ & N.S. \\
\hline Constipation & $3 / 7(42.9)$ & $10 / 43(23.3)$ & N.S. \\
\hline Micturition problems & $3 / 7(42.9)$ & $8 / 43(18.6)$ & N.S. \\
\hline Dry eyes & $2 / 7(28.6)$ & $17 / 43(39.5)$ & N.S. \\
\hline Dry mouth & $5 / 7(71.4)$ & $13 / 43(30.2)$ & N.S. \\
\hline Orthostatic dizziness & $3 / 7(42.9)$ & $14 / 43(32.6)$ & N.S. \\
\hline Palpitations & $2 / 7(28.6)$ & $12 / 43(27.9)$ & N.S. \\
\hline Hot flashes & $1 / 7(14.3)$ & $7 / 43(16.3)$ & N.S. \\
\hline Sensitive skin legs & $2 / 7(28.6)$ & $16 / 43(37.2)$ & N.S. \\
\hline Burning feet & 6/7 (85.7) & $20 / 43(46.5)$ & N.S. \\
\hline Intolerance for sheets & $3 / 7(42.9)$ & 9/43 (20.9) & N.S. \\
\hline Restless legs & $4 / 7(57.1)$ & $13 / 43(30.2)$ & N.S. \\
\hline SFN-SIQ total score, mean \pm SD & $8.0 \pm 7.1$ & $6.4 \pm 6.2$ & N.S. \\
\hline \multicolumn{4}{|l|}{ Quality of neuropathic pain, n (\%) } \\
\hline Burning & $6 / 8(75.0)$ & $27 / 55(49.1)$ & N.S. \\
\hline Pricking & $5 / 8(62.5)$ & $12 / 55(21.8)$ & 0.0278 \\
\hline Aching & $3 / 8(37.5)$ & 28/55 (50.9) & N.S. \\
\hline Electric-like & $1 / 8(12.5)$ & $24 / 55$ (43.6) & N.S. \\
\hline $\begin{array}{l}\text { Allodynia (pain due to a stimulus that does not usually } \\
\text { provoke pain) }\end{array}$ & $1 / 8(12.5)$ & 9/55 (16.4) & N.S. \\
\hline $\begin{array}{l}\text { Hyperalgesia (increased pain from a stimulus that } \\
\text { usually provokes pain) }\end{array}$ & $2 / 8(25.0)$ & $7 / 55$ (12.7) & N.S. \\
\hline
\end{tabular}

Abbreviations: IgG = immunoglobulin G; N.A. = not available; N.S. = not significant; SFN = small fiber neuropathy; SFN-SIQ = small fiber neuropathy-Symptoms Inventory Questionnaire.

The Mann-Whitney $U$ test was used to compare continuous variables, and the $\chi^{2}$ test or Fisher exact probability test (when criteria for the $\chi^{2}$ test were not fulfilled) was used to compare the categorical variables between patients with SFN with and without plexin D1-lgG.

SFN-SIQ symptoms: 1 = altered sweating pattern; 2 = diarrhea; $3=$ constipation; $4=$ micturition problems; $5=$ dry eyes; $6=$ dry mouth; $7=$ orthostatic dizziness; 8 = palpitations; $9=$ hot flashes; $10=$ sensitive skin legs; 11 = burning feet; $12=$ intolerance for sheets; $13=$ restless legs. The answer options of the SFN-SIQ include "never = 0," "sometimes = 1," "often = 2," and "always = 3." A symptom is considered present when the score is 1 or higher. 
A

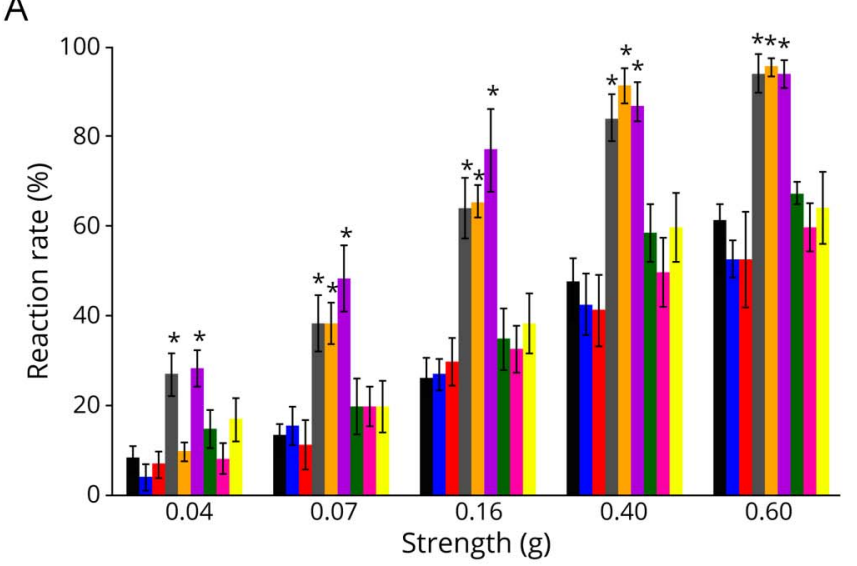

Control $\lg G(n=14)$

NBD Patient IgG $(n=7)$

NPSLE Patient IgG $(n=7)$

Patient $1 \lg G(n=7)$

Patient $2 \lg G(n=7)$

Patient $3 \operatorname{lgg}(n=7)$

Preabsorbed Patient 1 IgG $(n=7)$

Preabsorbed Patient $2 \lg G(n=7)$

Preabsorbed Patient $3 \operatorname{IgG}(n=7)$

B

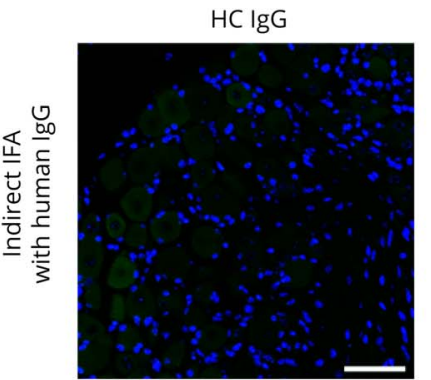

Patient 3 IgG

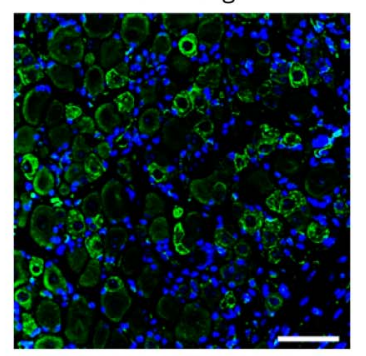

Preabsorbed

Patient 3 IgG
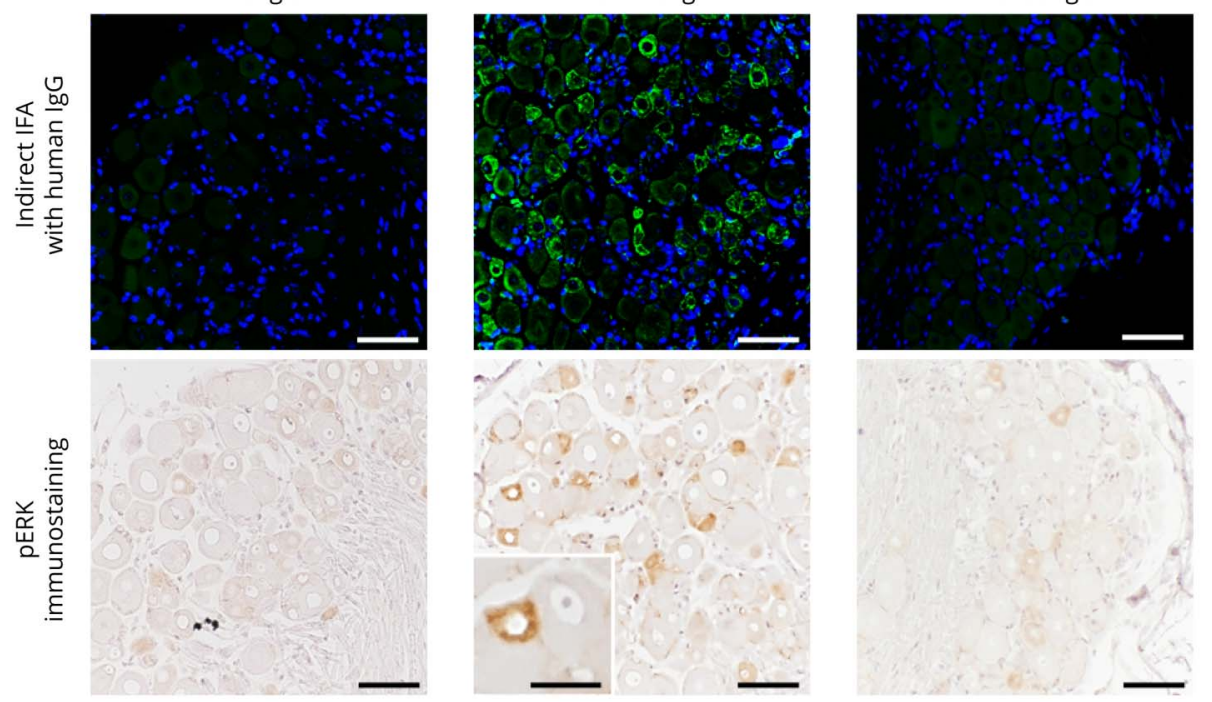

C

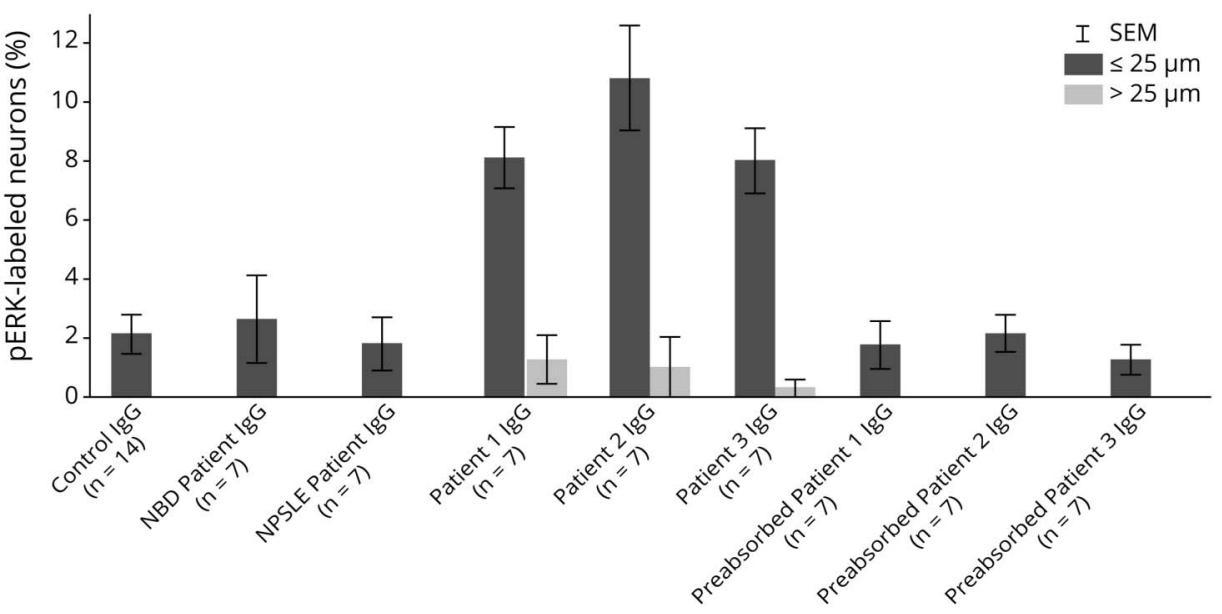

(A) Mechanical pain hypersensitivity was assessed by calibrated von Frey filaments $(0.04,0.07,0.16,0.40$, and $0.60 \mathrm{~g}) 24$ hours after injection. Mice treated with purified IgG from patients 1,2 , and 3 showed significantly higher reaction rates to each stimulation strength $(0.07,0.16,0.40$, and $0.60 \mathrm{~g}$ filaments) than HC IgG-treated mice (1way ANOVA with Dunnett test; ${ }^{*} p<$ 0.01 ). No significant differences in reaction rates were seen with IgG from 2 inflammatory disease controls (1 patient with NBD and 1 patient with NPSLE) and patients 1, 2, and 3 after preadsorption with rhPlexin D1 compared with control IgG (1-way ANOVA with Dunnett test). (B) Indirect IFA of mouse L5 DRG sections revealed that IgG (green) from the patient with SFN (patient 3) with plexin D1-IgG but not control IgG bound to small DRG neurons. IgG from patient 3 preabsorbed with rhPlexin D1 $(2 \mu \mathrm{g} / \mathrm{mL})$ showed no significant immunoreactivity to mouse DRG. Nuclei are counterstained with 4',6-diamidino-2-phenylindole (blue). Immunostaining of pERK, a marker of primary afferent neuron activation, in L5 DRG of mice treated with purified IgG from patient 3 and control 24 hours after injection. Most of the pERKlabeled neurons in mice treated with purified IgG from patient 3 are small DRG neurons ( $\leq 25 \mu \mathrm{m}$ in diameter). Few neurons are labeled for pERK in mice treated with control IgG and IgG from patient 3 after preabsorption with rhPlexin D1. Sections were counterstained with hematoxylin. (C) Distribution of pERK immunoreactivity among different-sized neurons was analyzed. DRG neurons were stratified as small ( $\leq 25 \mathrm{~mm}$ in diameter) and large ( $>25 \mathrm{~mm}$ in diameter) neurons. The pERK-labeled neurons in L5 DRG of mice treated with purified IgG from patients 1, 2, and 3 were predominantly small neurons of less than $25 \mu \mathrm{m}$ in diameter. Scale bars $=50 \mu \mathrm{m}$ and (inset) $=25 \mu \mathrm{m}$. ANOVA = analysis of variance; $\mathrm{DRG}=$ dorsal root ganglia; $\mathrm{HC}=$ healthy control; IFA = immunofluorescence assay; IgG = immunoglobulin G; NBD = neuro-Behçet disease; NPSLE = neuropsychiatric systemic lupus erythematosus; pERK = phosphorylated extracellular signalregulated protein kinase; Pre-Ab = preabsorbed; rhPlexin D1 = recombinant human plexin D1.

the latter was also reported in sensorimotor polyneuropathy. ${ }^{27}$ The ubiquitous existence of these relevant antigens ${ }^{28-30}$ and the absence of passive transfer experiments in animals make interpretation of their roles in SFN difficult.
The passive transfer to mice of mechanical pain associated with activation of small pain-conducting DRG neurons by plexin D1-IgG and abrogation of these effects by preadsorption of purified IgG with the extracellular domain of plexin D1 indicates the mechanical pain-provoking effects of 
plexin D1-IgG in vivo. This is consistent with the previous finding that $\mathrm{NeP}$ patient-derived plexin D1-IgG selectively binds to isolectin B4-positive unmyelinated C-fiber type small DRG neurons ${ }^{8,10}$ that sense mechanical pain. ${ }^{31,32}$ Accordingly, plexin D1-IgG is considered to be pathogenic. Because of marked heterogeneity in SFN etiologies, the frequencies of autoantibodies found in SFN, including plexin D1-IgG, are not high. Nonetheless, given that pain relief was achieved in plexin D1IgG-positive patients by immunotherapy, ${ }^{8,10}$ testing plexin D1IgG could be a useful guide for selecting patients with SFN eligible for immunotherapy, for whom no treatment options are available except for analgesics, which have only limited efficacy.

For mass-screening of plexin D1-IgG, development of an ELISA is necessary. ${ }^{33}$ The overall coincidence rate of the present ELISA to the standard TBA for plexin D1-IgG was sufficiently high so that this ELISA is potentially applicable for screening plexin D1-IgG. The occurrence of 2 false-positive cases is possibly because of nonspecific reactivity to the ELISA antigen, rhPlexin D1 derived from the NSO mouse myeloma cell line-which is abnormally glycosylated. ${ }^{34}$ Therefore, the production of rhPlexin $\mathrm{D} 1$ derived from human cell lines is required to increase the specificity of the ELISA assay for future studies.

Our study has several limitations. First, although all patients with SFN in this study fulfilled the established criteria for clinically based SFN, SFN was not confirmed by histopathology. However, patients with SFN with anticontactin-associated protein-like 2 antibodies demonstrated no (or limited) abnormalities in pathologic skin biopsies or whole sural nerve biopsies, ${ }^{35}$ despite functional nociceptive hyperexcitability. Thus, it would be better to examine intraepidermal nerve fiber density in antiplexin D1-IgGpositive SFN cases in the future, although it is possible that only limited abnormalities would be found. Second, the criteria for SFN used in this study required length-dependent clinical manifestations. Therefore, it is still possible that plexin D1-IgG may be present in patients with SFN or $\mathrm{NeP}$ showing nonlengthdependent pain manifestations. The possibility of more widespread manifestations of plexin D1-IgG should be investigated in a future large-scale study. Finally, we could not perform a large-scale, long-term evaluation of the passive transfer experiments with patient-derived plexin D1-IgG because of limited amounts of the patients' sera. Thus, our passive transfer experimental results should be regarded as preliminary, particularly concerning thermal pain-provoking effects. Nevertheless, because plexin D1-IgG could be a potential biomarker for immunotherapy consideration in SFN, prospective clinical trials are warranted to establish evidence for immunotherapy in patients with SFN with plexin D1-IgG.

\section{Acknowledgment}

The authors thank Jeremy Allen, $\mathrm{PhD}$, from Edanz Group (enauthor-services.edanz.com/ac) for editing a draft of this manuscript.

\section{Study Funding}

This study was funded in part by grants from the Japan Society for the Promotion of Science (JSPS) KAKENHI (Grant Nos. JP19H01045 and JP19K17037).

\section{Disclosure}

T. Fujii is supported by grants from JSPS KAKENHI (Grant No. JP19K17037), the Yamasa Corporation, Mitsubishi Tanabe Pharma, Osoegawa Neurology Clinic, Bayer Yakuhin, Ltd., and the Japan Blood Products Organization and received speaker honoraria payments from the Takeda Pharmaceutical Company and Eisai. E.-J. Lee and Y. Miyachi report no disclosures relevant to the manuscript. R. Yamasaki is supported by grants from JSPS KAKENHI (Grant No. JP19K07963) and the Yamasa Corporation. Y.-M. Lim, K. Iinuma, A. Sakoda, and K.-K. Kim report no disclosures relevant to the manuscript. J. Kira is supported by grants from JSPS KAKENHI (Grant No. JP19H01045), Health and Labour Sciences Research Grants on Intractable Diseases (H29Nanchitou [Nan]-Ippan-043), and the Yamasa Corporation and received consultancy fees, speaking fees, and/or honoraria from Novartis Pharma, Mitsubishi Tanabe Pharma, Boehringer Ingelheim, Teijin Pharma, the Takeda Pharmaceutical Company, Otsuka Pharmaceutical, Astellas Pharma, Pfizer Japan, and Eisai. Go to Neurology.org/NN for full disclosures.

\section{Publication History}

Received by Neurology: Neuroimmunology \& Neuroinflammation December 3, 2020. Accepted in final form April 5, 2021.

Appendix Authors

\begin{tabular}{|c|c|c|}
\hline Name & Location & Contribution \\
\hline $\begin{array}{l}\text { Takayuki } \\
\text { Fujii, MD, } \\
\text { PhD }\end{array}$ & $\begin{array}{l}\text { Kyushu University, } \\
\text { Fukuoka, Japan }\end{array}$ & $\begin{array}{l}\text { Designed and conceptualized the } \\
\text { study, analyzed the data, and drafted } \\
\text { the manuscript for intellectual } \\
\text { content }\end{array}$ \\
\hline $\begin{array}{l}\text { Eun-Jae Lee, } \\
\text { MD, PhD }\end{array}$ & $\begin{array}{l}\text { Asan Medical } \\
\text { Center, Seoul, South } \\
\text { Korea }\end{array}$ & $\begin{array}{l}\text { Major role in acquisition of clinical } \\
\text { data of patients }\end{array}$ \\
\hline $\begin{array}{l}\text { Yukino } \\
\text { Miyachi, } \\
\text { MSc }\end{array}$ & $\begin{array}{l}\text { Kyushu University, } \\
\text { Fukuoka, Japan }\end{array}$ & $\begin{array}{l}\text { Major role in data acquisition, ELISA, } \\
\text { the animal experiment, and IFA }\end{array}$ \\
\hline $\begin{array}{l}\text { Ryo } \\
\text { Yamasaki, } \\
\text { MD, PhD }\end{array}$ & $\begin{array}{l}\text { Kyushu University, } \\
\text { Fukuoka, Japan }\end{array}$ & Analyzed and interpreted the data \\
\hline $\begin{array}{l}\text { Young-Min } \\
\text { Lim, MD, } \\
\text { PhD }\end{array}$ & $\begin{array}{l}\text { Asan Medical } \\
\text { Center, Seoul, South } \\
\text { Korea }\end{array}$ & $\begin{array}{l}\text { Major role in acquisition of clinical } \\
\text { data of patients }\end{array}$ \\
\hline $\begin{array}{l}\text { Kyoko } \\
\text { linuma, MSc }\end{array}$ & $\begin{array}{l}\text { Kyushu University, } \\
\text { Fukuoka, Japan }\end{array}$ & $\begin{array}{l}\text { Major role in data acquisition and } \\
\text { ELISA }\end{array}$ \\
\hline $\begin{array}{l}\text { Ayako } \\
\text { Sakoda, MD, } \\
\text { PhD }\end{array}$ & $\begin{array}{l}\text { Kyushu University, } \\
\text { Fukuoka, Japan }\end{array}$ & $\begin{array}{l}\text { Major role in acquisition of clinical } \\
\text { data of patients }\end{array}$ \\
\hline $\begin{array}{l}\text { Kwang-Kuk } \\
\text { Kim, MD, } \\
\text { PhD }\end{array}$ & $\begin{array}{l}\text { Asan Medical } \\
\text { Center, Seoul, South } \\
\text { Korea }\end{array}$ & $\begin{array}{l}\text { Designed and conceptualized the } \\
\text { study and interpreted the data }\end{array}$ \\
\hline $\begin{array}{l}\text { Jun-ichi Kira, } \\
\text { MD, PhD }\end{array}$ & $\begin{array}{l}\text { Kyushu University, } \\
\text { Fukuoka, Japan }\end{array}$ & $\begin{array}{l}\text { Designed and conceptualized the } \\
\text { study, interpreted the data, and } \\
\text { revised the manuscript for } \\
\text { intellectual content }\end{array}$ \\
\hline
\end{tabular}




\section{References}

1. Terkelsen AJ, Karlsson P, Lauria G, et al. The diagnostic challenge of small fibre neuropathy: clinical presentations, evaluations, and causes. Lancet Neurol. 2017; 16(11):934-944.

2. Oaklander AL, Nolano M. Scientific advances in and clinical approaches to small-fiber polyneuropathy: a review. JAMA Neurol. 2019;76(10):1240-1251. doi: 10.1001/ jamaneurol.2019.2917

3. Sopacua M, Hoeijmakers JGJ, Merkies ISJ, et al. Small-fiber neuropathy: expanding the clinical pain universe. J Peripher Nerv Syst. 2019;24(1):19-33.

4. de Greef BTA, Hoeijmakers JGJ, Gorissen-Brouwers CML, et al. Associated conditions in small fiber neuropathy_a large cohort study and review of the literature. Eur J Neurol. 2018;25(2):348-355.

5. Peters MJ, Bakkers M, Merkies IS, et al. Incidence and prevalence of small-fiber neuropathy: a survey in the Netherlands. Neurology. 2013;81(15):1356-1360. doi: 10. 1212/WNL.0b013e3182a8236e.

6. Levine TD, Kafaie J, Zeidman LA, et al. Cryptogenic small-fiber neuropathies: serum autoantibody binding to trisulfated heparan disaccharide and fibroblast growth factor receptor-3. Muscle Nerve. 2020;61(4):512-515.

7. Tholance Y, Moritz CP, Rosier C, et al. Clinical characterisation of sensory neuropathy with anti-FGFR3 autoantibodies. J Neurol Neurosurg Psychiatry. 2020;91(1):49-57.

8. Fujii T, Yamasaki R, Iinuma $\mathrm{K}$, et al. A novel autoantibody against plexin D1 in patients with neuropathic pain. Ann Neurol. 2018;84(2):208-224.

9. Jimenez-Andrade JM, Herrera MB, Ghilardi JR, et al. Vascularization of the dorsal root ganglia and peripheral nerve of the mouse: implications for chemical-induced peripheral sensory neuropathies. Mol Pain. 2008;4:10. doi: 10.1186/1744-8069-4-10.

10. Fujii T, Yamasaki R, Miyachi Y, et al. Painful trigeminal neuropathy associated with anti-Plexin D1 antibody. Neurol Neuroimmunol Neuroinflamm. 2020;7(5):e819. doi: 10.1212/NXI.0000000000000819.

11. Bakkers M, Faber CG, Hoeijmakers JG, et al. Small fibers, large impact: quality of life in small-fiber neuropathy. Muscle Nerve. 2014;49(3):329-336.

12. Mathiesen R, Chriél M, Struve T, Heegaard PMH. Quantitative immunoassay for mink immunoglobulin in serum and milk. Acta Vet Scand. 2018;60:36. doi: 10.1186/ s13028-018-0391-7.

13. Kagiava A, Sargiannidou I, Theophilidis G, et al. Intrathecal gene therapy rescues a model of demyelinating peripheral neuropathy. Proc Natl Acad Sci USA. 2016; 113(17):E2421-E2429. doi: 10.1073/pnas.1522202113.

14. Yuki N, Chan AC, Wong AHY, et al. Acute painful autoimmune neuropathy: a variant of Guillain-Barré syndrome. Muscle Nerve. 2018;57(2):320-324.

15. Mestre C, Pélissier T, Fialip J, et al. A method to perform direct transcutaneous intrathecal injection in rats. J Pharmacol Toxicol Methods. 1994;32(4):197-200.

16. Yamasaki R, Fujii T, Wang B, et al. Allergic inflammation leads to neuropathic pain via glial cell activation. J Neurosci. 2016;36(47):11929-11945.

17. Deuis JR, Dvorakova LS, Vetter I. Methods used to evaluate pain behaviors in rodents. Front Mol Neurosci. 2017;10:284. doi: 10.3389/fnmol.2017.00284.

18. Sapio MR, Iadarola MJ, LaPaglia DM, et al. Haploinsufficiency of the brain-derived neurotrophic factor gene is associated with reduced pain sensitivity. Pain. 2019; 160(5):1070-1081.
19. Dai Y, Iwata K, Fukuoka T, et al. Phosphorylation of extracellular signal-regulated kinase in primary afferent neurons by noxious stimuli and its involvement in peripheral sensitization. J Neurosci. 2002;22(17):7737-7745.

20. Tsubaki M, Takeda T, Matsumoto M, et al. Trametinib suppresses chemotherapyinduced cold and mechanical allodynia via inhibition of extracellular-regulated protein kinase 1/2 activation. Am J Cancer Res. 2018;8(7):1239-1248.

21. Hofmann L, Hose D, Grießhammer A, et al. Characterization of small fiber pathology in a mouse model of Fabry disease. Elife. 2018;7:e39300. doi: 10.7554/ eLife.39300.

22. Flossdorf P, Haupt WF, Brunn A, et al. Long-time course of idiopathic small fiber neuropathy. Eur Neurol. 2018;79(3-4):161-165.

23. Pavlakis PP, Alexopoulos H, Kosmidis ML, et al. Peripheral neuropathies in Sjogren syndrome: a new reappraisal. J Neurol Neurosurg Psychiatry. 2011;82(7):798-802.

24. Oaklander AL, Klein MM. Evidence of small-fiber polyneuropathy in unexplained, juvenile-onset, widespread pain syndromes. Pediatrics. 2013;131(4):e1091-e1100 doi: 10.1542 peds.2012-2597

25. Faignart N, Nguyen K, Soroken C, et al. Acute monophasic erythromelalgia pain in five children diagnosed as small-fiber neuropathy. Eur J Paediatr Neurol. 2020;28: 198-204.

26. Pestronk A, Choksi R, Logigian E, Al-Lozi MT. Sensory neuropathy with monoclonal IgM binding to a trisulfated heparin disaccharide. Muscle Nerve. 2003;27(2) 188-195.

27. Kovvuru S, Cardenas YC, Huttner A, et al. Clinical characteristics of fibroblast growth factor receptor 3 antibody-related polyneuropathy: a retrospective study. Eur J Neurol. 2020;27(7):1310-1318

28. Saad OM, Ebel H, Uchimura K, et al. Compositional profiling of heparin/heparan sulfate using mass spectrometry: assay for specificity of a novel extracellular human endosulfatase. Glycobiology. 2005;15(8):818-826.

29. Solari V, Rudd TR, Guimond SE, et al. Heparan sulfate phage display antibodies recognise epitopes defined by a combination of sugar sequence and cation binding. Org Biomol Chem. 2015;13(21):6066-6072.

30. Antoine JC, Boutahar N, Lassablière F, et al. Antifibroblast growth factor receptor 3 antibodies identify a subgroup of patients with sensory neuropathy. J Neurol Neurosurg Psychiatry. 2015;86(12):1347-1355.

31. Vulchanova L, Olson TH, Stone LS, et al. Cytotoxic targeting of isolectin IB4-binding sensory neurons. Neuroscience. $2001 ; 108(1): 143-155$.

32. Tarpley JW, Kohler MG, Martin WJ. The behavioral and neuroanatomical effects of IB4-saporin treatment in rat models of nociceptive and neuropathic pain. Brain Res. 2004;1029(1):65-76.

33. Jarius S, Wildemann B. Aquaporin-4 antibodies (NMO-IgG) as a serological marker of neuromyelitis optica: a critical review of the literature. Brain Pathol. 2013;23(6) 661-683.

34. $\mathrm{Ng} \mathrm{JK}$, Malotka J, Kawakami N, et al. Neurofascin as a target for autoantibodies in peripheral neuropathies. Neurology. 2012;79(23):2241-2248.

35. Xu M, Bennett DLH, Querol LA, et al. Pain and the immune system: emerging concepts of IgG-mediated autoimmune pain and immunotherapies. J Neurol Neurosurg Psychiatry. 2020;91(2):177-188. 


\title{
Neurology \\ Neuroimmunology \& Neuroinflammation
}

\author{
Antiplexin D1 Antibodies Relate to Small Fiber Neuropathy and Induce Neuropathic \\ Pain in Animals \\ Takayuki Fujii, Eun-Jae Lee, Yukino Miyachi, et al. \\ Neurol Neuroimmunol Neuroinflamm 2021;8; \\ DOI 10.1212/NXI.0000000000001028
}

This information is current as of June 7, 2021

\section{Updated Information \& \\ Services}

References

Citations

Subspecialty Collections

Permissions \& Licensing

Reprints including high resolution figures, can be found at:

http://nn.neurology.org/content/8/5/e1028.full.html

This article cites 35 articles, 8 of which you can access for free at: http://nn.neurology.org/content/8/5/e1028.full.html\#\#ref-list-1

This article has been cited by 1 HighWire-hosted articles: http://nn.neurology.org/content/8/5/e1028.full.html\#\#otherarticles

This article, along with others on similar topics, appears in the following collection(s):

Autoimmune diseases

http://nn.neurology.org//cgi/collection/autoimmune_diseases

Neuropathic pain

http://nn.neurology.org//cgi/collection/neuropathic_pain

Peripheral neuropathy

http://nn.neurology.org//cgi/collection/peripheral_neuropathy

Information about reproducing this article in parts (figures,tables) or in its entirety can be found online at:

http://nn.neurology.org/misc/about.xhtml\#permissions

Information about ordering reprints can be found online:

http://nn.neurology.org/misc/addir.xhtml\#reprintsus

Neurol Neuroimmunol Neuroinflamm is an official journal of the American Academy of Neurology.

Published since April 2014, it is an open-access, online-only, continuous publication journal. Copyright

Copyright $\odot 2021$ The Author(s). Published by Wolters Kluwer Health, Inc. on behalf of the American

Academy of Neurology.. All rights reserved. Online ISSN: 2332-7812.

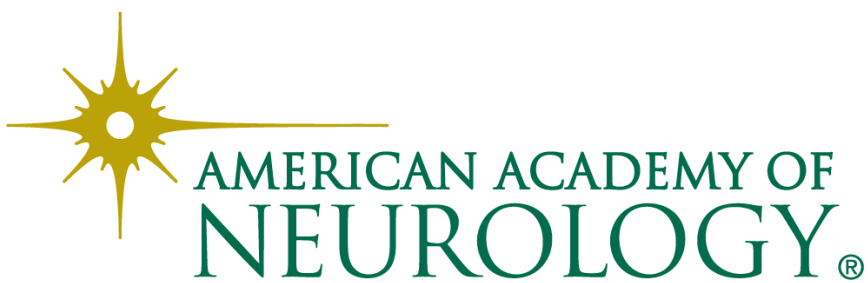

